\title{
Recovery of stimuli encoded with a Hodgkin-Huxley neuron using conditional PRCs
} Anmo J Kim and Aurel A Lazar*

\author{
Address: Department of Electrical Engineering, Columbia University, New York, NY, USA \\ Email: Aurel A Lazar* - aurel@ee.columbia.edu \\ * Corresponding author
}

from Eighteenth Annual Computational Neuroscience Meeting: CNS*2009

Berlin, Germany. 18-23 July 2009

Published: 13 July 2009

BMC Neuroscience 2009, 10(Suppl I):PI02 doi:I0.I I86/I47I-2202-I0-SI-PI02

This abstract is available from: http://www.biomedcentral.com/I47I-2202/I0/SI/PI02

(c) 2009 Kim and Lazar; licensee BioMed Central Ltd.

\section{Introduction}

The dynamics of Hodgkin and Huxley neuron for simple injected current waveforms such as steps and ramps has been extensively investigated in the literature [1]. A nonlinear perturbation analysis showed that a Hodgkin-Huxley neuron with deterministic gating variables is $\mathrm{I} / \mathrm{O}$ equivalent with a project-integrate-and-fire (PIF) neuron with a variable threshold sequence [2]. The PIF neuron integrates a projection of the stimulus onto the phase response curve that is, in turn, modulated by a phase shift process. The phase shift process is described by a differential equation that is stimulus driven. In the absence of the small perturbation term, the stimulus is tangentially coupled into the limit cycle of the Hodgkin-Huxely neuron and the PIF neuron reduces to an integrate-and-fire neuron.

Based on the I/O equivalent PIF neuron a stimulus recovery algorithm was given in [2]. The recovery works well provided that the stimulus restricts the PRC to a small parameter set. If, however, the Hodgkin-Huxley sweeps across a broad set of Phase Response Curves (PRCs as in Figure 1), a different recovery algorithm is needed for improved performance.

\section{Results}

The key limitation of the recovery algorithm in [2] is due to the static nature of the PRC. By introducing an adaptive kernel, the PIF can provide a faithful I/O description of the Hodgkin-Huxley neuron. In order to achieve an accu- rate I/O description, the PIF is endowed with an integration kernel that is inter-spike dependent. The kernel is, in effect, a conditional PRC that is parameterized by the inter-spike interval. Using the PIF with conditional kernel, our recovery algorithm was extensively tested for randomly generated stimuli. An example is shown in Figure 2 . The normalized recovery error was between $-20 \mathrm{~dB}$ and $-40 \mathrm{~dB}$.

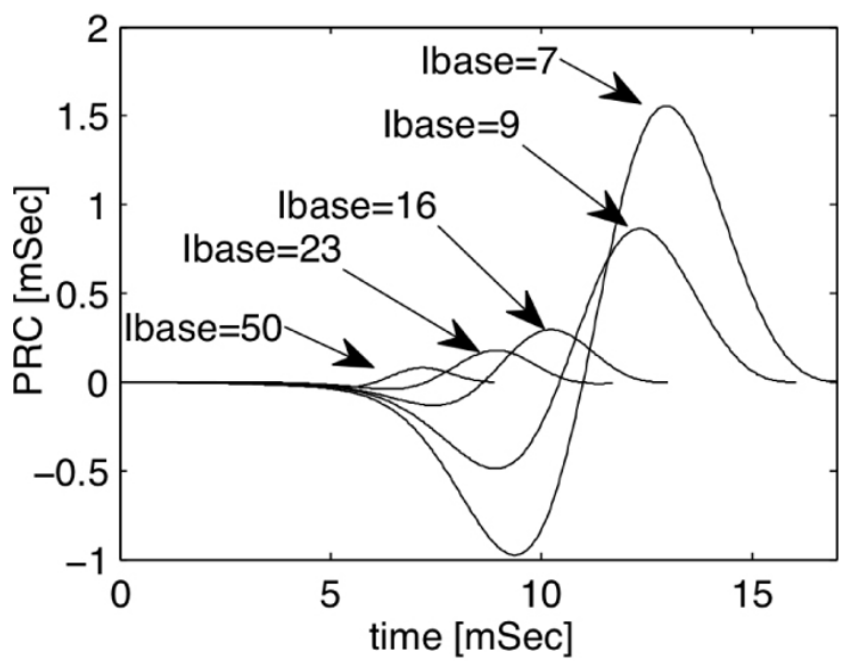

Figure I

PRCs with different base current (Ibase). 


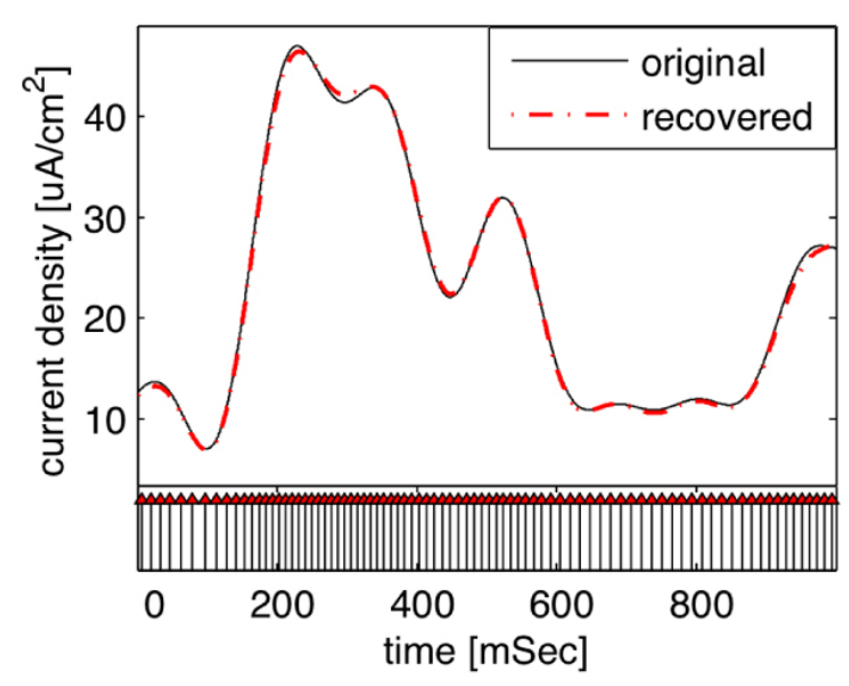

Figure 2

Recovery of input (top) from a spike train (bottom). The original input is constructed with $20 \mathrm{~Hz}$ bandwidth.

\section{Discussion}

The proposed algorithm is very flexible; it only requires the inversion of a matrix. It can be used for the recovery of stimuli encoded by a large class of neurons in the limit cycle region. It remains an open problem how the dendritic tree of a postsynaptic neuron is capable of recovering the information from its incoming spike sequence.

\section{Acknowledgements}

The work presented here was supported in part by $\mathrm{NIH}$ under grant number ROI DC00870I-0I and in part by NSF under grant number CCF06-35252.

\section{References}

I. Izhikevich EM: Dynamical Systems in Neuroscience: the Geometry of Excitability and Bursting MIT Press; 2007.

2. Lazar AA: Recovery of stimuli encoded with Hodgkin-Huxley neurons. Cosyne 2007:III-94.
Publish with Biomed Central and every scientist can read your work free of charge

"BioMed Central will be the most significant development for disseminating the results of biomedical research in our lifetime. "

Sir Paul Nurse, Cancer Research UK

Your research papers will be:

- available free of charge to the entire biomedical community

- peer reviewed and published immediately upon acceptance

- cited in PubMed and archived on PubMed Central

- yours - you keep the copyright

Submit your manuscript here:

http://www.biomedcentral.com/info/publishing_adv.asp 